\title{
Response of Arbuscular mycorrhizal fungi and Rhizobium inoculation on growth and chlorophyll content of Vigna unguiculata (L) Walp Var. Pusa 151
}

\author{
${ }^{1 * A R U M U G A M}, \mathrm{R} ;{ }^{2}$ RAJASEKARAN, $\mathrm{S} ;{ }^{2}$ NAGARAJAN, S M \\ ${ }^{1}$ Center of Advance Study in Marine Biology, Annamalai University, \\ Parangipettai- 608 502, Tamil Nadu, India \\ ${ }^{2}$ Department of Botany, A.V.C. College (Autonomous), Mannampandal-609 305, \\ Mayiladuthurai, Tamil Nadu, India. E-mail: rmugam@gmail.com
}

\begin{abstract}
The aim of the present study was to investigate the effect of Rhizobium and Arbuscular mycorrhizal fungi inoculation, both individually and in combination on growth and chlorophyll content of economically important plant Vigna unguiculata L. A significant $(\mathrm{p}<0.05)$ increase over control in root length $(45.6 \mathrm{~cm})$, shoot height $(12.2 \mathrm{~cm})$, dry weight of root $(0.4 \mathrm{~g})$ and shoot $(1.8 \mathrm{~g})$, total number of nodules $(39.6$ nos.), dry weight of nodules $(0.5 \mathrm{~g})$, percentage of mycorrhizal infection $(96.6 \%)$, chlorophylls $a(0.83 \mathrm{mg} / \mathrm{g}$ fr.wt. ), $b$ (1.19 mg/g fr.wt) and total chlorophyll $(2.24 \mathrm{mg} / \mathrm{g}$ fr.wt) was recorded in dual inoculated (AM fungi and Rhizobium) plants than plants with individual inoculation. Thus it is clear that the dual inoculation with AM fungi and Rhizobium biofertilizer is more effective than the individual treatment. @JASEM
\end{abstract}

The indiscriminate use of chemical fertilizer /pesticides leads to disastrous consequences of environmental quality, promoting the study of natural sources of fertilizer, bio-stimulants and soil amendments. Organic wastes and biofertilizers are the alternative sources to meet the nutrient requirement of crops. Arbuscular Mycorrhizal (AM) fungi are found in many soils around the w orld, and they form association with $80 \%$ of all terrestrial plant roots (Harley and Harley, 1987). The beneficial effects of AM fungi symbiotic association on the growth of plants are well known (Powell and Bagyaraj, 1984; Safir, 1987; Smith and Smith, 1996; Rajasekaran and Nagarajan, 2004; Francis and Read, 1995). AM fungi helps in water regulation of plants by extending their hyphae towards the available moisture zone for continuous water absorption and translocating them to plants. AM association can affect the host plants in terms of stomatal movement and photosynthesis of leaves and has been shown to increase the rate of transpiration, photosynthesis and chlorophyll content (Panwar, 1991; Bethlenfalvay et al., 1988).

Legumes are important pulse cultivated throughout Indian subcontinent, cost effective cultivation of this agricultural crops depends on effective symbiotic nitrogen fixation in their nodules that relies on the rhizobial populations of the soil (Postgate, 1982; Thevanathan, 1980; Bhavani, 1983). Mycorrhizal infection has particular value for legumes because nodulation and symbiotic nitrogen fixation by rhizobia require an adequate phosphorus supply and restricted root system leads to poor competition for soil phosphorus (Carling et al., 1978). Vigna unguiculata $(\mathrm{L})$ is commonly called as cowpea, a climbing bushy annual, usually cultivated for its beneficial fruits and for soil reclamation. In the light

E-mail: rmugam@gmail.com of these, the present investigation was undertaken to study the dual inoculation of Rhizobium and AM fungi on the growth, nutrition and chlorophyll content of Vigna unguiculata.

\section{MATERIALS AND METHODS}

The present study was conducted during January 2005 in the Dept. of Botany, A.V.C. College, Mannampandal, Mayiladuthurai, Tamil Nadu, India. The seeds of Vigna unguiculata (L) Walp var. Pusa 151 (Cowpea) were obtained from the Agriculture Research Station, Vamban, Pudukkotai D istrict, Tamilnadu, India. Seeds free from visible defects and uniform size were surface sterilized and sown in circular earthen pots $(40 \mathrm{~cm}$ height and $30 \mathrm{~cm}$ diameter) filled with a mixture of sterile garden soil and sand mixture at the ratio of $2: 1(\mathrm{v} / \mathrm{v})$. Seeds were inoculated individually with Rhizobium and AM fungi (applied as layering on soil surface) and combination of both. One pot of seedlings was left without inoculation as control. The plants were irrigated with tap water as and when required. The leaves were collected from each replication for sampling on 15th, 30th, and 45th day after sowing and estimation of chlorophyll content was done following the method of Arnon (1949). Plant shoot and root length, dry weight of shoot and root, total number of nodules per plant, dry weight of nodules per plant and root colonization of AM was calculated at 45th day. Root colonization of AM fungi was estimated by tryphan blue technique (Phillips and Hayman, 1970). Data were analysed statistically using Student ' $\mathrm{t}$ ' test. All the measurements were carried out in triplicates and the results were expressed in the average of the three replication. 


\section{RESULTS AND DISCUSSION}

The plants inoculated either with Rhizobium or AM fungi significantly increased the shoot length and root length, dry weight of shoot and root, total number of nodules and dry weight of nodules when compare to control. The dual inoculation of AM fungi and Rhizobium showed maximum values in all the tested parameter than plants inoculated with individual endophytes (Table 1). Fewer nodules with increased biomass were formed in dual inoculated plants, compared to plants inoculated individually with Rhizobium and AM fingi and uninoculated control plants. This contradicts other reports, where more nodules are reported on dual inoculation than non- mycorrhial plants (Asimi et al., 1980; Hazarika et al., 2000). However Patterson et al, (1990) reported AM fungi due to indirect response of the host plants affected a similar observation in the lower parts of the roots.

The plants inoculated with individual treatment of AM fungi and dual inoculation only shows positive for AM fungi colonization in roots. The Rhizobium inoculated plants and uninoculated control plants do not have colonization. The high frequency of $96 \%$ of infection was observed in roots of dual inoculated plants roots and $91 \%$ in AM fungi inoculated plants roots (Table 1).

\begin{tabular}{|c|c|c|c|c|}
\hline & Control & Rhizobium & AM fungi & $\begin{array}{l}\text { AM fungi + } \\
\text { Rhizobium }\end{array}$ \\
\hline Shoot length $(\mathrm{cm})$ & $27.6 \pm 0.7$ & $30.9 \pm 0.9^{*}$ & $41.0 \pm 1.1 *$ & $45.6 \pm 1.1^{*}$ \\
\hline Root length $(\mathrm{cm})$ & $8.3 \pm 0.3$ & $9.5 \pm 0.4 *$ & $11.6 \pm 0.8^{*}$ & $12.2 \pm 0.5^{*}$ \\
\hline Dry weight of shoot $(\mathrm{g})$ & $1.4 \pm 0.02$ & $1.6 \pm 0.05^{*}$ & $1.7 \pm 0.02 *$ & $1.8 \pm 0.02 *$ \\
\hline Dry weight of $\operatorname{root}(\mathrm{g})$ & $0.3 \pm 0.01$ & $0.4 \pm 0.01 *$ & $0.4 \pm 0.01 *$ & $0.4 \pm 0.01 *$ \\
\hline Total number of nodules/plant & $1.3 \pm 0.02$ & $32.6 \pm 2.5^{*}$ & $2.5 \pm 0.5$ & $39.6 \pm 1.5^{*}$ \\
\hline Dry weight of nodules $(\mathrm{g})$ & $0.02 \pm 0.01$ & $0.3 \pm 0.01 *$ & $0.02 \pm 0.01$ & $0.5 \pm 0.01 *$ \\
\hline Mycorrhizal effect (\%) & - & - & $92.0 \pm 1.7$ & $96.6 \pm 2.1$ \\
\hline
\end{tabular}

Plants inoculated with AM fungi, either alone or in combination with Rhizobium, brought about significant changes in chlorophyll a, b and total chlorophyll content. The maximum total chlorophyll content was noticed at 45 th days old sampling leaves in dual inoculated plants followed by individual inoculation of AM fungi and Rhizobium (Table 2). A considerable increase in chlorophyll content of AM fungi and Rhizobium inoculated tissue of cowpea is in agreement with results reported elsewhere (Hayman, 1983). This increase may be due to an increase in stomatal conductance, photosynthesis, transpiration and enhanced plant growth (Hayman, 1983; Sampath and Ganesh, 2003; Rajasekaran et al., 2006) or due to the presence of large and more numerous bundle sheath chloroplasts in the inoculated leaves (Krishna and Bagyaraj, 1984).

\begin{tabular}{|c|c|c|c|c|c|c|c|c|c|c|c|c|}
\hline & \multicolumn{3}{|c|}{ Control } & \multicolumn{3}{|c|}{ Rhizobium } & \multicolumn{3}{|c|}{ AM fungi } & \multicolumn{3}{|c|}{ AM fungi + Rhizobium } \\
\hline & \multicolumn{3}{|c|}{ Days after inoculation } & \multicolumn{3}{|c|}{ Days after inoculation } & \multicolumn{3}{|c|}{ Days after inoculation } & \multicolumn{3}{|c|}{ Days after inoculation } \\
\hline & 15 & 30 & 45 & 15 & 30 & 45 & 15 & 30 & 45 & 15 & 30 & 45 \\
\hline \multirow[t]{2}{*}{ Chl 'a' } & $0.63 \pm$ & $0.74 \pm$ & $0.83 \pm$ & $0.73 \pm$ & $0.78 \pm$ & $0.99 \pm$ & $0.65 \pm$ & $0.83 \pm$ & $0.90 \pm$ & $0.79 \pm$ & $0.93 \pm$ & $1.09 \pm 0.02 *$ \\
\hline & 0.04 & 0.03 & 0.03 & $0.02 *$ & $0.02 *$ & $0.02 *$ & 0.02 & $0.04 *$ & $0.02 *$ & $0.02 *$ & $0.02 *$ & \\
\hline \multirow[t]{2}{*}{ Chl 'b' } & $1.06 \pm$ & $1.13 \pm$ & $1.19 \pm$ & $1.12 \pm$ & $1.22 \pm$ & $1.34 \pm$ & $1.15 \pm$ & $1.26 \pm$ & $1.22 \pm$ & $1.23 \pm$ & $1.26 \pm$ & $1.65 \pm 0.02 *$ \\
\hline & 0.02 & 0.01 & 0.02 & $0.02 *$ & $0.01^{*}$ & $0.02 *$ & $0.03 *$ & $0.01 *$ & $0.01 *$ & $0.01 *$ & $0.02 *$ & \\
\hline Total & $2.07 \pm$ & $2.16 \pm$ & $2.24 \pm$ & $2.15 \pm$ & $2.32 \pm$ & $2.43 \pm$ & $2.17 \pm$ & $2.35 \pm$ & $2.28 \pm$ & $2.28 \pm$ & $2.35 \pm$ & $2.73 \pm 0.04 *$ \\
\hline Chl & 0.02 & 0.02 & 0.02 & $0.01 *$ & $0.02 *$ & $0.03 *$ & $0.01 *$ & $0.01 *$ & $0.02 *$ & $0.02 *$ & $0.01 *$ & \\
\hline
\end{tabular}

There are several reports indicates that the chlorophyll content was higher in the leaves of resistance varieties than those of susceptible varieties, as biochemical characters like phenol, proteins and chlorophyll may play a vital role in making plants resistant to pathogens (Bhavani, 1983; Rajasekaran and Nagarajan, 2005; Charitha and Reddy, 2001). It is reported that use of AM fungi inoculants saving fertilizer phosphorus to a tune of $25-30 \mathrm{~kg} \mathrm{P} 2 \mathrm{O} / \mathrm{ha}$. Besides supplying $\mathrm{p}$ to plants, these fungi also serve as biocontrol agents against certain soil-borne plant pathogens and can survive under inhospitable soil environments. Thus the present study clearly reveals that the dual inoculation with AM fungi and Rhizobium biofertilizer is more effective in increasing growth, nutrition, chlorophyll content and biomass production of legumes. It is also essential to study the possibility of inoculating the legume crops with selected strains of AM fungi and Rhizobium to for higher pulse production. 
Acknowledgement: The authors are thankful to Dr. V. Karunanithi, Head, Depertment of Botany for providing the facilities.

\section{REFERENCE}

Arnon, DI (1949). Coper enzyme in isolated chloroplasts. Polyphenol oxidase in Beta vulgasis. Plant physiology, 24: $1-5$.

Asimi. S; Gianinazzi Pearson, V; Gaininazzi, S (1980). Influnce of increasing soil phosphorous level on interaction between vesicular arbuscular mycorrhiza and Rhizobium in soybean. Canadian journal of Botany, 58: 2200-2205.

Bethlenfalvay, GJ; Brown, MS; Franson, RL (1988). Glycine- glomus- Bradyrhizobium symbiosis. Plant physiology, 94: 723-728.

Bhavani, ILG (1983). Assimilation of ammonia and synthesis of ureides in root nodules of field bean (Lablab purpureus (L) Sweet). Ph.D thesis, University of Madras.

Bisht, R; Chaturvedi, S; Srivastava, R; Sharma, AK; Johri, BN (2009). Effect of arbuscular mycorrhizal fungi, Pseudomonas fluorescens and Rhizobium leguminosarum on the growth and nutrient status of Dalbergia sissoo Roxb. Tropical Ecology, 50(2): 231242.

Charitha, DM; Reddy, MN (2001). Growth response of groundnut to VAM fungus and Rhizobium inoculation. Plant pathology Bulletin, 10: 71-78.

Carling, DE; Richel, NE, Johnson, DR (1978). Effect of VAM on nitrate reductase and nitrogenase activity in nodulation and non nodulation soybean. Physiology, 68:1590-1596.

Francis, R; Read, DJ (1995). Mutualism and antagonism in the mycorrhizal symbiosis with special reference to impacts on plant community structure. Canadian Journal of Botany, 73: 1301-1309.

Harley, JL; Harley, EL (1987). A check-list of mycorrhiza in the British flora. New Phytol, 105: 1-102.

Hayman, DS (1983). The physiology of vesicular arbuscular endomycorrhizal symbiosis. Canadian Journal of Botany, 61: 944-963.

Hazarika, DK; Das, KK; Dubey, LN; Phookan, AK (2000). Effect of Vesicular arbuscular mycorrhizal fungi and Rhizobium on growth and yield of green gram (Vigna radiata $\mathrm{L}$ ). Journal of mycology and plant pathology, 30 (3): 424-426.

Krishna, KR; Bagyaraj, DJ (1984). Growth and nutrient uptake of peanut inoculated with mycorrhizal fungus
Glomus fasciculatum compared with uninaculated ones. Plant and Soil, 17: 405-408.

Panwar, JDS (1991). Effect of VAM and Azospirillum brasilense on photosynthesis, nitrogen metabolism and grain yield in wheat. Indian Journal of Plant Physiology, 34: 357-361.

Patterson, NA; Cheit, I; Kapulink, Y (1990). Effect of Mycorrhizal inoculation on nodule initiation activity and contribution to legume productivity symbiosis. Annals of Biology, 8: 9-20.

Phillips, JM; Hayman, DS (1970). Improved procedures for clearing roots and staining parasitic and vesicular arbuscular mycorrhizal fungus for rapid assessment of infection. Trans. Br. Mycol. Soc, 55: 158-161

Postgate, JR (1982). The fundamentals of nitrogen fixation. Cambridge University press, Cambridge.

Powell, CL; Bagyaraj, DJ (1984). VA mycorrhizal. CRC Press, Boca Raton, FL.

Rajasekaran, S; Nagarajan, SM (2004). Occurance and histochemical studies on VAM fungi and some medicinal plants. Asian J. Microbiol. Biotech. Env. Sci., 6(4): 553-556.

Rajasekaran, S; Nagarajan, SM (2005). Effect of dual inoculation (AM fungi and Rhizobium) on Chlorophyll content of Vigna unguiculata (L.) Walp. Var. Pusa. 151. Mycorrhiza News, 17(1): 10-11.

Rajasekaran, S; Nagarajan, SM; Arumugam, K; Sravanamuthu, R; Balamurugan, S. (2006). Effect of dual inoculation (AM fungi and Rhizobium) on Chlorophyll content of Arachis hypogaea L. CV. TMV-2. Plant Archives, 6(2): 671-672.

Safir, GR (1987). Ecophysiology of VA mycorrhizal plants. CRC Press, Boca Raton, FL.

Sampath kumar, G; Ganesh kumar, A. (2003). Effect of AM fungi and Rhizobium on growth and nutrition of Vigna mungo L. and Vingna unguiculata L. Mycorrhiza News, 14(4): 15-18.

Smith, FA;. Smith, SE.(1996). Mutualism and parasitism, diversity in function and structure in the arbuscular mycorrhizal symbiosis. Advanced Botany Research, 21: 1-43.

Thevanathan, R (1980). Assimilation of fixed nitrogen and Asparagine synthesis in nodules of cluster bean (Cyamopsis tetragonoloba Taub.). Ph.D. thesis, University of Madras.

Zarea, MJ; Ghalavand, A; Goltapeh, ME; Rejali, F. (2009). Interaction of mycorrhiza, earthworm and rhizobium on growth of annual medic under light stress. Journal of Agricultural Technology, 5(2): 249-259. 